\title{
SINEMA RELIGI DALAM PUSARAN INDUSTRI MEDIA
}

\author{
Ropingi el Ishaq \\ Dosen Tetap Sekolah Tinggi Agama Islam (STAIN) Kediri
}

\begin{abstract}
Normatively, media functions as a means of conveying information, education, and entertainment as well as controlling and relating the society. On the basis of its function, media has a chance to build a direct communication with the society so that it has a strategic position that may give benefits not only to the social aspect, but also to economic and political aspects.

One way to develop communication with the public is through soap opera program. This TV program is chosen since it can highly attract public interest. In the point of view of media industry, public or audience are considered as customers who have to be served by the producer. The more the customers are satisfied, the more the producer gets benefit. One theme of soap operas that can highly attract public interest is religion-related theme.

It reflects the normative society understanding of religion. As a result, the religious message contained in the soap operas is very formal. Moreover, since it can highly attract public attention, it can be utilized by media industry to get as much profit as they can and it does not function to give education and wholesome entertainment.
\end{abstract}

Key Words: media, soap opera, religion, media indudtry

\begin{abstract}
Abstrak
Secara normatif, media memiliki fungsi menyampaikan informasi, pendidikan, hiburan yang sehat, kontrol dan perekat sosial. Atas dasar fungsi tersebut, media diberi ruang untuk membangun komunikasi secara langsung dengan publik. Ruang inilah yang kemudian menjadikan media memiliki posisi strategis yang bisa dimanfaatkan bukan hanya dari sisi sosial, tetapi juga ekonomi dan politik.

Salah satu cara media membangun komunikasi dengan publik adalah melalui tayangan sinetron. Tayangan ini dipilih karena memiliki tingkat ketertarikan publik yang tinggi. Dalam konteks industri media, publik diposisikan sebagai konsumen yang harus dilayani oleh media sebagai produsen. Semakin konsumen terpuaskan, maka sesungguhnya memberikan keuntungan yang berlipat terhadap produsen.

Tayangan sinetron yang mendapat apresiasi tinggi dari publik adalah sinetron bertema religi. Hal ini tidak terlepas dari konstruksi pemahaman agama di tingkat masyarakat yang relatif masih normatif sehingga rasa keagamaan yang hadir bersifat formal. Segala sesuatau termasuk sinetron apabila mengadaptasi atau mengakomodasi nilai-nilai keagamaaan maka publik akan mengapresiasinya secara tidak kritis bahkan dalam beberapa hal berlebihan. Kondisi ini kemudian dimanfaatkan oleh industri media melalui sinetron bertema religi untuk memperoleh tingkat penerimaan publik. Tujuannya bukan dalam rangka pendidikan atau memberikan hiburan yang sehat tetapi lebih kepada akumulasi keuntungan yang berlipat.
\end{abstract}

Kata-Kata Kunci: media, sinetron, religi, industri media. 


\section{Pendahuluan}

Sebagaimana biasa, pada awal atau menjelang ramadhan, stasiun televisi seolah berlomba merebut hati pemirsa (muslim) yang menjalankan ibadah puasa dengan suguhan tayangan televisi bernuansa keagamaan. Presenter televisi yang biasanya tidak mengenakan jilbab, pada bulan ramadhan mengenakan jilbab. Berbagai acara yang biasanya digelar dengan terbuka, pakaian yang mengedepankan aspek sensualitas, dan budaya hura-hura secara mendadak berubah menjadi lebih santun, sopan, dan tertutup.

Di antara tayangan yang ikut berpartisipasi memeriahkan bulan ramadhan dengan acara yang lebih bernuansa keagamaan adalah sinetron. Salah satu sinetron yang ditayangkan di awal bulan ramadhan tahun 2011 adalah sinetron Khadijah dan Khalifah yang ditayangkan oleh stasiun televisi Indosiar. Sinetron ini diproduksi oleh Multivision Plus dengan 'menggunakan' bintang-bintang baru yang masih muda. Sinetron ini bersaing dengan sinetronsinteron lain yang ditayangkan dalam waktu bersamaan oleh stasiun televisi lain, yakni Dari Sujud Ke Sujud yang ditayangan RCTI pukul 18.00, MNC TV yang menayangkan Sampeyan Muslim pada pukul 19.00 dan sineton Ranum yang ditayangkan oleh MNC TV juga. ${ }^{1}$

Sinetron ini cukup menarik di samping sinetron-sinetron lain yang ditayangkan oleh stasiun televisi Indosiar pada tahun ini. Hal yang menarik dan menggelitik untuk ditelisik lebih jauh adalah sinetron ini ditayangkan di bulan ramadhan sebagai tayangan religi untuk menemani umat muslim menjalankan ibadah puasa di bulan ramadhan. Sinetron ini sarat dengan simbol-simbol keagamaan seperti kerudung, baju koko, kopyah, mukenah, dan juga sajadah. Di samping itu, banyak bahasa verbal keagamaan yang digunakan dalam berbagai dialog, seperti kata astaghfirullah, subhanallah, dan juga maasyaa Allah. Makin mantaplah bahwa sinetron ini merupakan sinetron religi yang, tentunya mengemas pesan-pesan moral dan keagamaan yang patut direnungkan oleh pemirsa televisi. Yang menjadi pertanyaan adalah bagaimana pesan sinema ini dibangun? Sebagai pesan-pesan dakwah atau sebagai sebuah komoditas yang dirumuskan sesuai dengan momen ramadhan? Melalui tulisan ini penulis akan mengkaji sinetron dalam konteks industri sinema.

\section{Buah Karya Bernama Sinema}

Istilah sinema mulai populer setelah sebelumnya dikenal dengan istilah sinetron. Kata sinetron merupakan gabungan dari dua kata yakni sinema dan elektronik. Sinema diserap dari kata Inggris cinema yang berarti film atau bioskop dan elektronik dimaknai media elektronik berarti barang yang mengandung electron (ion yang bermuatan listrik negatif) yakni televisi. ${ }^{2}$ Dalam Kamus Besar Bahasa Indonesia sinetron diartikan dengan film yang dibuat secara khusus untuk ditayangkan di media elektronik (televisi). ${ }^{3}$

Berdasarkan pada pengertian tersebut, ada dua hal pokok menyangkut sinetron, yakni film yang dibuat bersambung dan ditayangkan di televisi. Sehingga apabila film itu tidak ditayangkan oleh media televisi, maka tidak dapat disebut dengan sinetron. Film yang diproduksi untuk ditayangkan di televisi secara tunggal (tidak serial) disebut dengan film televisi (FTV).

Perkembangan sinema di negeri ini mengalami pasang surut. Pada awal kemerdekaan sampai pada akhir era tahun 1980-an, sinema banyak diproduksi dalam bentuk layar lebar. Ada beberapa sinema yang diproduksi dalam bentuk drama berseri. Pada era tahun 1990-an, telenovela (kata lain dari sinetron yang diimpor dari luar) masuk ke Indonesia dan menjadi tayangan favorit. Pada waktu itu belum banyak production house $(\mathrm{PH})$ sehingga tayangan ini didatangkan dari luar. Banyak sekali telenovela didatangkan dari luar dan di antaranya 
berjudul 'Maria Cinta Yang Hilang', 'Cassandra', 'Esmeralda', 'Marimar' yang ditayangkan oleh stasiun televisi swasta pada waktu menjadi menu tayangan favorit masyarakat Indonesia. ${ }^{4}$

Berdirinya production house $(\mathrm{PH})$ dan stasiun-stasiun televisi swasta di negeri ini sekitar tahun 1990-an telah mengantarkan perkembangan sinema di negeri ini kian pesat. Ditambah lagi dengan perkembangan teknologi komunikasi dan informasi yang terus berjalan memberikan sumbangsih yang besar bagi perkembangan sinema (film). Peralatan yang tersedia seperti kamera dan software editing yang banyak tersedia dengan harga relatif murah mempermudah pembuatan sinema. Keberadaan peralatam ini menjadikan sinema mudah diproduksi.

Pasca era telenovela muncul banyak sinetron yang diproduksi production house dalam negeri. Sinetron 'Tersanjung' menjadi sinetron favorit di awal tahun 1990-an. Dilanjutkan dengan sinetron 'Si Doel Anak Sekolahan' yang merupakan sinetron budaya karena mengangkat aspek budaya lokal. Sinetron ini menjadi sinetron favorit dan fenomenal. Berikutnya sinetron 'Cinta Fitri'.

Kini, telah banyak sinema elektronik (sinetron), film televisi (FTV) maupun film layar lebar (movies) yang diproduksi oleh para sineas. Ada sinema anak, remaja, serta dewasa. Ada sinema yang bergenre umum, ada pula yang bergenre religi. Semuanya dapat dinikmati melalui layar televisi, gedung bioskop, maupun kepingan VCD/DVD yang dijual bebas.

\section{Fashion: Sebuah Tanda Dalam Sinema}

Sinema elektronik menjadi tayangan favorit hingga saat ini. Sebuah survey menyatakan bahwa wanita banyak yang menyukai tayangan sinetron. Hal ini disebabkan alur cerita yang menonjolkan konflik, mengemas mimpi dan imaginasi yang secara visual seolah menjadi kehidupan nyata, keindahan-keindahan hidup yang seringkali melebihi kenyataan, dan perwujudan mimpi (yang biasanya ditokohkan oleh perempuan), sehingga menyentuh aspek emosional pemirsa dan menjadi perhatian khususnya bagi kaum perempuan. ${ }^{5}$

Salah satu hal yang biasanya menarik perhatian pemirsa, khususnya perempuan adalah aspek fashion (pakaian) yang dipakai oleh para bintang sinetron. Mode pakaian yang dipakai para bintang biasanya menjadi trend di tengah masyarakat. Contoh mutakhir adalah jilbab model segitiga dengan salah satu ujungnya ditarik ke bagian belakang kepala dan dikancing dengan bross. Model ini mengadaptasi dari sinetron 'Surga Untukmu' yang ditayangkan oleh Stasiun televisi Indosiar pada ramadhan tahun 2010 yang lalu dan sinetron 'Khadijah dan Khalifah' yang ditayangkan oleh Indosiar pada tahun 2011 ini.

Dalam sinetron 'Khadijah dan Khalifah' setidaknya ada tiga pola pakaian wanita. Pertama jilbab sebagaimana yang selalu dikenakan oleh Khalifah, kedua pakaian panjang tertutup tanpa jilbab sebagaimana dipakai oleh Khadijah dan ketiga pakaian sensual terbuka sebagaimana dikenakan para tokoh pembantu. Pola-pola pakaian tersebut merepresentasikan karakter masing-masing tokoh.

Jilbab dan pakaian panjang tertutup ditampilkan untuk merepresentasikan sosok yang religi dan baik. Sementara pakaian sensual terbuka merepresentasikan sosok yang egois dan hedonis. Dalam kajian semiotika, jilbab dapat diinterpretasikan sebagai indikasi keshalihan seorang muslimah. Karena jilbab adalah salah satu pakaian yang dianjurkan oleh agama. Tetapi tidak berarti bahwa jilbab menjadi indikator mutlak untuk menunjukkan keshalihahan seorang muslimah. Tidak berjilbab tidak mesti mengindikasikan seseorang itu tidak shalihah.

Makna sebaliknya juga dapat dibangun dari interpretasi tersebut. Orang berjilbab belum tentu menunjukkan keshalihan seseorang. Jilbab bahkan menjadi 'topeng' penutup niat 
jahat seseorang sehingga menjadi lebih aman untuk dapat melakukan tindak kejahatan. Dalam racikan certita sinetron 'Khadijah dan Khalifah' makna ini diartikulasi dalam sosok Wulan dan Bunga, dua wanita cantik yang mengenakan busana muslimah (jilbab) dalam kerangka menyamar demi sebuah tujuan kejahatan, yakni merebut harta orang lain. Praktis, pakaian hanyalah sebagian kecil dari tanda kepribadian seseorang. Makna ini dapat diperoleh dengan menyimak alur cerita dalam sinetron yang ditayangkan.

Dalam konteks makro, sinetron sebagai sebuah karya yang multi pesan, jilbab dapat dimaknai sebagai sebuah pesan komersil dalam sebuah program tayangan. Model jilbab yang dikenakan oleh para artis menjadi sebuah pesan tertentu yang sama sekali terlepas dari makna pesan yang terbangun dalam alur cerita. Makna pesannya tak lain adalah 'pakailah jilbab atau pakaian seperti yang dipakai para artis ini, anda akan menjadi cantik'. Dengan makna pesan ini maka jadilah model pakaian para artis saat dia syuting sinetron bukan hanya bermakna menggambarkan sosok yang diperankan, tetapi bermakna iklan yang dimaksudkan untuk mempengaruhi pemirsa agar mengenakan pakaian (jilbab) sebagaimana para artis.

Pertanyaan kemudian adalah mengapa sinetron digemari oleh wanita? Tak lain karena di dalamnya 'menghidangkan' berbagai adegan yang menegangkan dan juga berbagai gambaran ideal, khususnya yang berkaitan dengan artis idola. Pada konteks ini, tak heran jika pada akhirnya model kerudung yang dikenakan oleh artis sinetron menjadi trend di tengah masyarakat. Model jilbab ala Ranun pada sinetron 'Surga Untukmu' dan Khalifah pada sinetron 'Khadijah dan Khalifah' menjadi laris manis.

Jilbab atau pakaian adalah penanda (signifier) yang dapat dimaknai (signified) secara beraneka ragam makna. Tidak hanya dua makna tersebut di atas, tetapi dapat dimaknai yang lain, tergantung dari pengalaman pemirsa. Pengalaman menjadi bagian penting dalam proses semiotik atas tanda, baik yang berupa model pakaian maupun yang lainnya. Sehingga perbedaan pengalaman dapat memunculkan makna yang berbeda atas tanda yang sama. ${ }^{6}$ Lebih lanjut pemaknaan dari suatu tanda tersebut dapat diperoleh secara konotatif di samping makna denotatif. Makna konotatif lebih digunakan sesuai dengan paradigma berpikir dan budaya masyarakat, sehingga lebih bersifat sosiologis. ${ }^{7}$ Hal ini tergantung bagaimana budaya yang berkembang dalam sebuah kelompok masyarakat.

\section{Pesan dan Iklan Sinetron Religi}

Sinetron nampaknya masih menjadi tayangan favorit bagi setiap stasiun televisi di negeri ini. Setelah pada awal tahun 1990-an mulai muncul televisi-televisi swasta dan menghadirkan program-program impor seperti telenovela, kini program serupa dengan produksi dalam negeri menjadi 'raja' tayangan televisi. Hampir tidak ada stasiun televisi yang absen menayangkan program sinetron ini. Sejak pagi hingga malam hari sinetron selalu tampil terdepan.

Sinetron menjadi bagian dari program andalan televisi. Sinetron apa yang laku di 'pasar' pemirsa, maka sinetron sejenis akan muncul. Dulu ketika sinetron 'Misteri Gunung Merapi' menjadi master dalam program tayangan, muncul sinetron-sinetron sejenis. Pasang surut sinetron hampir sama dengan pasang surut sinema secara umum. Ketika judul-judul bombastis sinema muncul dengan ikon mistis, maka muncul sinema-sinema layar lebar lainnya yang berbau mistis pula. Bahkan hingga sekarang sinema mistis masih menjadi alternatif. Bisa dilihat judul-judul sinema layar lebar seperti 'Suster Ngesot' dan judul-judul sejenis masih mendominasi. 
Pada dasarnya kelebihan sinema secara umum maupun sinema elektronik terletak pada kekuatan ceritanya. Alur cerita yang bagus akan mampu menydeot perhatian pemirsa. Dapat ditelisik lebih jauh mengapa sinema fantasi ilmiah yang banyak digarap para insan sinema dari luar begitu menarik perhatian. Bagaimana sinema layar lebar dalam negeri seperti 'Pasir Berbisik', 'Sang Pencerah', atau sinetron elektronik yang mengangkat budaya lokal seperti 'Si Doel Anak Sekolah', termasuk sinetron 'Tersanjung', serta 'Cinta Fitri' mampu menyedot perhatian pemirsa? Ini tak lain adalah karena kekuatan ceritanya. Hal ini dapat dibuktikan, bahwa ternyata sinetron 'Tersanjung' dan 'Cinta Fitri' mulai menurun ratingnya karena alur ceritanya sudah ngelantur kemana-mana.

Mengapa cerita sinetron menjadi ngelantur? Rating adalah godaannya. Sebuah tayangan televisi pada awalnya lebih menjual alur cerita. Jika alurnya bagus, maka sebuah program tayangan akan kian laku. Tetapi pada saat sinetron telah laku, menjadi perhatian, dan bahkan kegandrungan para pemirsa, maka alur ceritanyapun sedikit demi sedikit kian tidak jelas. Pembuat program merasa enggan mengakhiri sebuah tayangan yang sudah terlanjur memperoleh rating tinggi. Akhirnya, ceritanya diperpanjang sedemikian rupa untuk mempertahankan rating.

Berbicara rating, pada akhirnya akan menyinggung masalah pemirsa sebagai market. Suatu tayangan yang ratingnya bagus maka berarti marektnya bagus. Pada akhirnya, market menjadi pertimbangan utama dalam menentukan sebuah sinetron yang ditayangkan televisi. Antara rating dan market tidak dapat dipisahkan. Tanpa rating dan market, sinetron tidak akan jalan. Tanpa market (pemirsa) tak mungkin sebuah tayangan televisi akan diprogramkan, karena jika dipaksakan untuk dijalankan, maka misi utama dalam bidang penyiaran televisi akan gagal. Televisi tidak akan mampu menggali keuntungan. ${ }^{8}$

Dalam rumus jual beli, pembeli adalah raja yang harus dilayani sebaik mungkin, meskirpun permintaannya sebenarnya bertentangan dengan gagasan ideal penjual. Sebuah tayangan sinema haruslah dikemas sesuai dengan minat pemirsa. Sinetron harus dikemas secara menarik. Menarik versi pemirsa. Meskipun sebuah program televisi dinyatakan berkualitas, tetapi jika pemirsa tidak menyatakan menarik, maka program televisi tidak akan dilanjutkan. Pemirsa adalah pembeli, meskipun mereka tidak membayar secara langsung apa yang dibelinya. Pembayar langsungnya adalah pihak pengiklan yang sesungguhnya uangnya dibebankan pada masyarakat melalui harga suatu produk konsumtif. Pada konteks lain pemirsa dapat pula dikatakan sebagai komoditi yang dijual pihak televisi kepada pemasang iklan. Seberapa banyak pemirsa dapat dikumpulkan akan menentukan seberapa banyak akan dibeli oleh pihak pengiklan. Sekali lagi di sinilah nilai penting pemirsa dalam roda perekonomian media televisi. ${ }^{9}$

Masalahnya adalah bahwa para pemirsa televisi tidaklah seperti pemirsa film di gedung bioskop. Menurut Wirodono pola kepemirsaan sinetron yang ada di rumah bersifat sambil lalu, sehingga para praktisi media (pembuat sinetron) harus melakukan berbagai upaya menarik perhatian pemirsa. Berbeda dengan penonton film. Film ditonton oleh mereka yang memang secara psikologis siap untuk menikmati film, sehingga tanpa harus disuguhi dengan cerita yang ringan dan menarik sekalipun, pemirsa film tidak akan meninggalkan film di tengah jalan. Sementara sinetron harus dikemas semenarik mungkin agar pemirsa tidak 'berpaling' dan meninggalkan sinetron sebelum usai. ${ }^{10}$

Salah satu strategi yang dilakukan untuk memperoleh pemirsa adalah dengan memunculkan tokoh-tokoh cerita yang bersifat multi backgound. Ada cerita orang kaya, miskin, orang yang taat beragama, preman, penjahat, pemuda nakal dan taubat, dan 
sebagainya dihadirkan untuk menyemarakkan cerita. Tokoh-tokoh tersebut dihadirkan, sekali lagi, untuk memperoleh pemirsa dari berbagai strata sosial. Sinetron multi strata sosial ini diharapkan akan dapat membujuk pemirsa agar fanatik melihat adegan demi adegan sampai tuntas atas tayangan yang disajikan. Dengan demikian pihak stasiun televisi dapat 'menjualnya' kepada pihak pengiklan. Inilah yang dijelaskan oleh Sujarwa ${ }^{11}$ bahwa televisi dengan program-programnya, khususnya sinetron tak lepas dari kapitalisasi media.

\section{Idealisme dan Pragmatisme Media}

Ada hal yang menarik menyangkut media, khususnya televisi. Novel Ali menyatakan bahwa media telah kehilangan idealisme karena cenderung mementingkan aspek ekonomi ketimbang kualitas konten acara. Hal ini ditunjukkan dengan banyaknya acara televisi yang tidak berkualitas. ${ }^{12}$ Hal senada dikemukakan oleh Nia Mutmainnah Armando, Komisioner KPI, bahwa televisi cenderung merumuskan acara yang berbasis hiburan belaka, termasuk acara keagamaan, sehingga dikhawatirkan justru akan 'mengebiri' agama itu sendiri menjadi sebuah 'agama' baru. ${ }^{13}$ Sementara, Menteri Agama, Suryadharma Ali, menyatakan bahwa acara televisi di bulan Ramadhan, khususnya komedi, cenderung kurang merepresentasikan syiar Islam. ${ }^{14}$

Hal yang berbeda dikemukakan oleh Amir Effendi Siregar (Ketua Pemantau Regulasi dan Regulator Media (PR2MEDIA). Ia berpandangan bahwa kecenderungan media untuk mengutamakan kepentingan ekonomi tidaklah berarti mengorbankan idealismenya. Sebab, lembaga pers yang baik atau ideal adalah yang memberikan sesuatu kepada masyarakat luas. Dan dengan perhitungan ekonomi, tidak salah jika suatu media memuat atau menayangkan program hiburan untuk membidik pangsa pasar tertentu yang menyukai hiburan. Demikian juga jika suatu media membuat dan menyiarkan program berita untuk membidik pangsa pasar tertentu yang menyukainya, selama masih berada pada koridor kode etik jurnalistik dan P3SPS. ${ }^{15}$

Memang betul, bahwa suatu media khususnya media penyiaran seperti televisi, tidak menjadi masalah menayangkan hiburan dan berorientasi ekonomi. Dalam Undang-Undang No 32 tahun 2002 pasal 4 ayat 1 dan 2 disebutkan;

1. Penyiaran sebagai kegiatan komunikasi massa mempunyai fungsi sebagai media informasi, pendidikan, hiburan yang sehat, kontrol dan perekat sosial.

2. Dalam menjalankan fungsi sebagaimana dimaksud dalam ayat (1), penyiaran juga mempunyai fungsi ekonomi dan kebudayaan.

Tetapi fungsi tersebut tidak boleh melupakan aspek tujuan penyiaran yang telah ditetapkan oleh pemerintah, yakni sebagaimana dikemukakan pada pasal 3; "Penyiaran diselenggarakan dengan tujuan untuk memperkukuh integrasi nasional, terbinanya watak dan jati diri bangsa yang beriman dan bertakwa, mencerdaskan kehidupan bangsa, memajukan kesejahteraan umum, dalam rangka membangun masyarakat yang mandiri, demokratis, adil dan sejahtera, serta menumbuhkan industri penyiaran Indonesia."

Untuk itu, dalam pasal 5 Undang-Undang Penyiaran mengatur tentang arah penyiaran yang harus dilakukan, yakni untuk:

1. menjunjung tinggi pelaksanaan Pancasila dan Undang-Undang Dasar Negara Republik Indonesia Tahun 1945;

2. menjaga dan meningkatkan moralitas dan nilai-nilai agama serta jati diri bangsa;

3. meningkatkan kualitas sumber daya manusia;

4. menjaga dan mempererat persatuan dan kesatuan bangsa; 
5. meningkatkan kesadaran ketaatan hukum dan disiplin nasional;

6. menyalurkan pendapat umum serta mendorong peran aktif masyarakat dalam pembangunan nasional dan daerah serta melestarikan lingkungan hidup;

7. mencegah monopoli kepemilikan dan mendukung persaingan yang sehat di bidang penyiaran;

8. mendorong peningkatan kemampuan perekonomian rakyat, mewujudkan pemerataan, dan memperkuat daya saing bangsa dalam era globalisasi;

9. memberikan informasi yang benar, seimbang, dan bertanggung jawab;

10. memajukan kebudayaan nasional.

Dengan beberapa aturan yang tertuang dalam pasal 3, 4, dan 5 UU No 32 tahun 2003 tentang penyiaran tersebut dapat digaris bawahi bahwa lembaga atau media penyiaran seharusnya berorientasi pada fungsi media penyiaran, yakni sebagai media informasi, pendidikan, hiburan yang sehat, kontrol dan perekat sosial. Adapun fungsi ekonomi hanyalah sebagai fungsi penyerta saja. Dengan demikian, meskipun orientasi ekonomi dapat dibenarkan dalam penyelenggaraan media penyiaran, tetapi tidak boleh lepas dari fungsi utama yang telah ditetapkan.

Tetapi yang terjadi justru berbeda. Media penyiaran lebih mengutamakan fungsi hiburan dalam kerangka fungsi ekonomi dengan tanpa menghiraukan fungsi utamanya. Media penyiaran terkesan mengabaikan dan cenderung melakukan pelanggaran atas Pedoman Perilaku Penyiaran dan Standar Program Siaran (P3SPS) yang ditetapkan oleh Komisi Penyiaran Indonesia (KPI) sebagai lembaga yang ditunjuk oleh pemerintah dan Dewan Perwakilan Rakyat (DPR) untuk mengatur regulasi media penyiaran, seolah begitu nyata. Kecenderungan ini jelas mengindikasikan bahwa media yang ada memang cenderung kehilangan idealisme dan mengutamakan kepentingan pragmatis sebagaimana yang dikemukakan oleh Novel Ali.

Jika saja media penyiaran tidak mengindikasikan gejala pragmatisme tentu tidak akan banyak terjadi pelanggaran P3SPS sebagaimana yang terjadi akhir-akhir ini. Dan pada giliran selanjutnya tidak akan banyak komentar miring dari masyarakat luas maupun dari para tokoh masyarakat menyangkut berbagai tayangan televisi. Di sinilah perlunya dibangun paradigma baru agar media betul-betul menjalankan fungsinya dengan baik. Menurut Deddy Mulyana, perguruan tinggi (termasuk pihak-pihak terkait khususnya praktisi media) perlu menganalisis pesan media secara adil, cerdas, dan kritis untuk membangun media yang ideal dan khalayaknya. ${ }^{16}$

\section{Penutup}

Sinema religi berkembang seiring dengan perkembangan media. Banyaknya media penyiaran yang berdiri saat ini memberikan ruang bagi tumbuh suburnya sinema. Semakin canggihnya teknologi komunikasi akan meningkatkan kesempurnaan sinema dari aspek pembuatan pesan. Kesempurnaan sinema secara audio dan visual inilah yang menjadikan sinema kuat mengakar di mata pemirsa televisi. Karena dengan kesempurnaan tersebut pesanpesan sinema mampu 'menggiring' emosi pemirsa sehingga menjadikan mereka rela menjadi pemirsa fanatik sebuah program tayangan.

Semakin sempurnanya sinema ternyata belum menjadikan media penyiaran sebagai sarana penyampaian pesan sesuai dengan amanah undang-undang penyiaran, yakni sebagai media informasi, pendidikan, hiburan yang sehat, serta kontrol dan perekat sosial. Media 
penyiaran masih berkutat pada fungsi ekonomi sebagai fungsi penyerta media penyiaran. Berbagai program tayangan belum mampu keluar dari kuatnya dominasi kapitalisasi media. Sehingga pesan-pesan sinema masih cenderung terbelenggu dengan kepentingan komersil media.

\section{ENDNOTE}

1 http:/www.tabloidbintang.com/film-tv-musik/ulasan/14428-4-sinetron-ramadhan-tayang-bareng-mana-yangunggul.htmlg

${ }^{2} \mathrm{http}$ ://id.wikipedia.org/wiki/Sinema elektronik

${ }^{3}$ Kamus Pusat Bahasa, Kamus Besar Bahasa Indonesia, (Jakarta: Departemen Pendidikan Nasional, 2008), hlm. 1459.

${ }^{4}$ Abdul Aziz Saefuddin, Republik Sinetron, (Yogyakarta: Leutika, 2010), hlm. 23.

${ }^{5} \mathrm{http}: / /$ nasional.kompas.com/read/2010/11/29/08411239/Kenapa.Perempuan.Suka.Sinetron.

${ }^{6}$ Benny H. Hoed, Semiotik dan Dinamika Sosial Budaya, (Depok: Komunitas Bambu, 2011), hlm. 3.

${ }^{7}$ Ibid., hlm. 5.

${ }^{8}$ Erica L. Panjaitan \& TM Dani Iqbal, 2006, Matinya Rating Televisi: Ilusi Sebuah Netralitas, (Jakarta: Obor), hlm. 22.

${ }^{9}$ Abdul Aziz Saefuddin, $\boldsymbol{O p}$ Cit, hal 11.

${ }^{10}$ Sunardian Wirodono, Matikan TV-Mu: Teror Media Televisi di Indonesia, (Jakarta: Resist Book, 2006), hlm. 27.

${ }^{11}$ Sujarwa, Mitos di Balik Kisah-Kisah Sinetron: Dalam Perspektif Hegemoni dan Kapitalisasi, (Yogyakarta: Pustaka Pelajar, 2010), hlm. 27-29.

12 Novel Ali, Ideologi Media Massa, SKH. Kompas, Kamis tanggal 15 April 2010, http://cetak.kompas.com/read/xml/2010/04/15/04533157/Ideologi.Media.Massa

${ }_{13}$ Nina Mutmainnah Armando, Jika Acara Televisi Menjadi Substansi Agama, Koran Tempo, 03 September 2011

${ }_{15}^{14}$ http://pusdai.com/?p=6883, August 9, 2011.

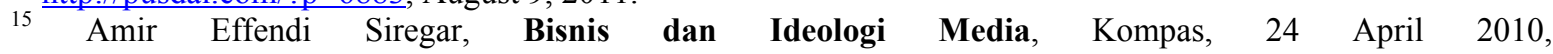
http://cetak.kompas.com/read/xml/2010/04/24/03262811/bisnis.dan.ideologi.media

${ }^{16}$ Deddy Mulyana, Komunikasi Massa; Kontroversi, Teori, dan Aplikasi, (Bandung: Widya Padjadjaran, 2008), hlm. 16.

\section{DAFTAR PUSTAKA}

Saefudin, Abdul Aziz. 2010. Republik Sinetron. Yogyakarta: Leutika.

Siregar, Amir Effendi. Bisnis dan Ideologi Media. Kompas, 24 April 2010. http://cetak.kompas.com/read/xml/2010/04/24/03262811/bisnis.dan.ideologi.media

Hoed, Benny H. 2011. Semiotik dan Dinamika Sosial Budaya. Depok: Komunitas Bambu.

Mulyana, Deddy. 2008. Komunikasi Massa; Kontroversi, Teori, dan Aplikasi. Bandung: Widya Padjadjaran.

Panjaitan, Erica L. \& Iqbal, TM Dani. 2006. Matinya Rating Televisi: Ilusi Sebuah Netralitas. Jakarta: Obor.

http://id.wikipedia.org/wiki/Sinema_elektronik

http://nasional.kompas.com/read/2010/11/29/08411239/Kenapa.Perempuan.Suka.Sinetron.

http://pusdai.com/?p=6883, August 9, 2011.

http://www.tabloidbintang.com/film-tv-musik/ulasan/14428-4-sinetron-ramadhan-tayangbareng-mana-yang-unggul.htmlg 
Kamus Pusat Bahasa. 2008. Kamus Besar Bahasa Indonesia. Jakarta: Departemen Pendidikan Nasional.

Armando, Nina Mutmainnah. Jika Acara Televisi Menjadi Substansi Agama. Koran Tempo, 03 September 2011

Ali, Novel. Ideologi Media Massa. Kompas, Kamis tanggal 15 April 2010, $\mathrm{http}: / /$ cetak.kompas.com/read/xml/2010/04/15/04533157/Ideologi.Media.Massa

Sujarwa. 2010. Mitos di Balik Kisah-Kisah Sinetron: Dalam Perspektif Hegemoni dan Kapitalisasi. Yogyakarta: Pustaka Pelajar.

Wirodono, Sunardian. 2006. Matikan TV-Mu: Teror Media Televisi di Indonesia, Jakarta: Resist Book. 